\title{
Comparative study on some immunological traits in two different genetic groups of chicken
}

\author{
Salah Abdel Rahman El-Safty \\ Department of Poultry Production, \\ Faculty of Agricuture, Ain Shams University, Hadayek Shoubra PO Box 68, Cairo, Egypt, \\ E-mail: salahsafty2004@yahoo.com,_Tel: 201-223421084, Fax: 202-44444460 \\ Received: 31-03-2012, Accepted: 09-05-2012, Published Online: 22-09-2012 \\ doi: $10.5455 /$ vetworld.2012.645-650
}

\begin{abstract}
Aim: This study was carried out on one hundred and twenty chicks (60 Libyan native and 60 broiler chicks) to evaluate and compare some productive and immunological characteristics.

Materials and Methods: Weekly body weight (from day-old until 6 weeks of age), feed conversion ratio (from 3- 6 weeks of age), phagocytic ability index, count of both heterophils and lymphocytes and its ratio and blood profile were determined.

Results: Body weight of Libyan native chickens was dramatically reduced as compared to broiler chickens throughout trial period. Feed conversion ratio of Libyan native chickens was pronounced deteriorated during studied period as compared to broiler ones. The phagocytic ability of Libyan native chickens was more efficient than those of broiler chickens counterparts. The Libyan native chickens were less stressful compared to broiler ones, because of significant decrease of $\mathrm{H} / \mathrm{L}$ ratio trait in Libyan chickens.

Conclusion: It was expected that the broiler chickens were superior in productive traits (body weight and feed conversion ratio) as compared to native chickens. On the other hand, the superiority in immunological parameters such as phagocytic activity and $\mathrm{H} / \mathrm{L}$ ratio (as a stress measure) was obtained by Libyan native chickens. Consequently, more attention must be considered for Libyan native chicken and using different crossing and selection methods to produce meat and egg native lines for improving its productive traits besides keeping and benefit its outstanding immunological abilities.
\end{abstract}

Keywords: body weight, broiler, immunity, native chickens, phagocytic ability.

\section{To cite thisarticle:}

El-Safty SAR (2012) Comparative study on some immunological traits in two different genetic groups of chicken, Vet World, 5(11): 645-650, doi: 10.5455/vetworld.2012.645-650

\section{Introduction}

The local fowls of the tropics retain its preference in its native environment despite of a drastic increase in import of high yielding strains from across the world. It still has the favor of the local people, especially in the rural sector, mainly due to its believed special capabilities as adaptability to unfavorable environments, resistance to certain disease and meat and egg quality. The products from native fowl are widely preferred especially because of their pigmentation, taste and their suitability for special dishes and are often sold at even higher prices than the same products from commercial birds [1].

The birds immune system is a complex network of specialized organs, glands and cells which are working together to protect the body from the pathogens [2]. This system is composed of three basic sub-systems, the humoral, cellular and phagocytic ability [3]. To enhance the efficiency of chicken immune system, several lines of chickens have been selected divergently against specific antigens [4]. Consequently, these selection processes must affect the major functions of the immune system, which leads to changes in the selected and correlated traits, resulting in differences in the immune responses among the commercial lines. In developing countries, the native chicken breeds contain conserved genetic system, with highly level of heterozygosity, which may provide biological material for the design of genetic with improved adaptability and productivity [5].

Worthy mentioning, characterization and evaluation of immune parameters in various genotypes can offer knowledge that can be incorporated into breeding programs for enhancing the natural resistance to 
disease in tropical and subtropical environment. Therefore, the present trial was conducted to evaluate and compare some productive and immunological characteristics in two genetic groups of chicken derived from different genetic origin.

\section{Materials and Methods}

Chicks and Management: This trial was carried out at Poultry Breeding Farm, Animal Production Department, Faculty of Agriculture, Sabha University, Libya. A total number of 120 newly hatched chicks (60 Cobb "500" broiler chicks and 60 Libyan native chicks) were used in this study. All chicks were brooded and raised under similar conditions from hatching up to the end of the trial (at 6 weeks of age). Managerial and hygienic practices for all chicks were similar. Feed and water were provided ad libitum. They were fed a starter diet containing $22 \%$ crude protein and $2950 \mathrm{Kcal} \mathrm{ME} / \mathrm{Kg}$ from hatch to four weeks of age, then finisher diet containing $18 \%$ crude protein and $3200 \mathrm{Kcal} \mathrm{ME} / \mathrm{Kg}$ up to the end of study. The range of high ambient temperature after brooding phase was $20-24^{\circ} \mathrm{C}$.

\section{Experimental Endpoints}

Body weight: Chick weights were determined from one-day old to 6 weeks of age using an electronic pan balance that was accurate to $0.01 \mathrm{~g}$.

Feed conversion ratio: Using 60 birds from the two genetic groups (30 each), feed conversion ratio (FCR) was estimated weekly during 3- 6 weeks of age using the following equation: $\mathrm{FCR}=$ Feed consumption $\div$ Body weight gain.

Phagocytosis: Carbon Clearance (Mononuclear Phagocytic System Function Assay) experiment was carried out to determine phagocytic ability of chicks based on the method of [6] and modified by [3] Briefly, the supernatant fraction of Black India ink (Design/Hggins, 4415, Sanford, Bellwood, Illinios 60104) was obtained through centrifugation (5000 rpm for $30 \mathrm{~min}$ ). At 6 weeks of age, five chicks from each genetic group were injected with ink at the rate of $1 \mathrm{ml} / \mathrm{kg}$ body weight into the left wing vein. The blood samples at 0,3 and $10 \mathrm{~min}$ after ink-injection were taken from the opposite wing and immediately transferred into $2 \mathrm{ml}$ of $1 \%$ sodium citrate. The samples were then centrifuged at $5000 \mathrm{rpm}$ for $4 \mathrm{~min}$. The relative amount of carbon particles remaining in the supernatant was measured spectrophoto-meterically at a wavelength of $640 \mathrm{~nm}$ using samples at $0 \mathrm{~min}$ as the zero value.

Heterophils/ Lymphocytes ratio: At 6 weeks of age, a $3.0 \mathrm{ml}$ blood sample was withdrawn from the brachial vein using sterile disposable syringes and needles and heparinized lab tubes to determine both $\mathrm{H} / \mathrm{L}$ ratio and blood profile. A total number of $10 \mathrm{blood}$ samples were obtained (5 from each genetic group) for heterophil $(\mathrm{H})$ and lymphocyte $(\mathrm{L})$ enumeration based on the procedures of [7]. Briefly, one drop of blood was smeared on each glass slide. After drying, the smears were stained using Wright's stain. Three hundred leukocytes, including granular (heterophils) and nongranular (lymphocytes) ones, were counted at $\mathrm{x} 40$ (oil immersion lens) and the $\mathrm{H} / \mathrm{L}$ ratio was calculated.

Blood profile: Using the same previous samples, the hematological values were estimated by Photmeter 4010 device (Made in Germany), that uses for blood analysis. The erythrocytic values include PCV: Packed cell volume, RBC: Red blood corpuscles, Hb: Hemoglobin concentration, MCV: Mean value of corpuscular volume, $\mathrm{MCH}$ : Mean value of corpuscular hemoglobin, MCHC: Mean value of corpuscular hemoglobin concentration were determined. In addition, the enumeration of white blood cells was determined.

Statistical Analysis: To determine the effect of chicken breed, data were subjected to one-way analysis of variance with breed as a main effect using the General Linear Model (GLM) procedure of SAS User's Guide, [8]. The following model was used;

$\mathrm{Y}_{\mathrm{ij}}=+\mathrm{B}_{\mathrm{i}}++\mathrm{e}_{\mathrm{ij}}$

Where; = overall mean, $\mathrm{B}_{\mathrm{i}}=$ breed effect $(\mathrm{i}=1,2)$, $\mathrm{e}_{\mathrm{ij}}=$ experimental error.

\section{Results and Discussion}

Data given in Table-1 showed the body weight of broiler and Libyan native chicks upon hatching until 6 weeks of age. Definitely, the superiority in body weight trait was associated with broiler chicks at all studied ages. It is unfair to compare between body weight for broilers and native chickens, where no selection improvement is adopted. The body weight of broiler chicks was twice the weight of the local upon hatching. It could be also observed that the difference between commercial and local chicks in body weight trait was increased with age progress, where the body weight of broiler chicks was almost six times and nine times at 21 and 42 days of age as compared to native chick's counterparts. In broiler strains, body weight and carcass traits were under intensive selection for more than half a century, and are considered as the most important economic traits in broiler breeding programs [9]. Moreover, progress in rapid growth has 
Table-1. Means $\pm S E$ of body weight Table-2. Heterophils $(H)$, lymphocytes $(L)$ and $H / L$ ratio of native and in broiler and Libyan native chicks

\begin{tabular}{lll}
\hline Age (day) & B roiler & Native \\
\hline 1 & $52.00^{\mathrm{a}} \pm 0.71$ & $26.70^{\mathrm{b}} \pm 0.33$ \\
7 & $116.00^{\mathrm{a}} \pm 3.10$ & $33.80^{\mathrm{b}} \pm 0.56$ \\
14 & $293.20^{\mathrm{a}} \pm 8.20$ & $61.40^{\mathrm{b}} \pm 1.20$ \\
21 & $599.80^{\mathrm{a}} \pm 15.70$ & $107.70^{\mathrm{b}} \pm 2.10$ \\
28 & $1042.90^{\mathrm{a}} \pm 28.30$ & $155.70^{\mathrm{b}} \pm 3.20$ \\
35 & $1526.80^{\mathrm{a}} \pm 43.30$ & $196.60^{\mathrm{b}} \pm 4.10$ \\
42 & $2224.70^{\mathrm{a}} \pm 59.20$ & $250.40^{\mathrm{b}} \pm 5.40$ \\
\hline
\end{tabular}

\begin{tabular}{llll}
\hline Strain & Heterophils (H) & Lymphocytes (L) & H/L ratio \\
\hline Native & $14.3^{\mathrm{b}} \pm 2.0$ & $85.7^{\mathrm{a}} \pm 2.0$ & $0.17^{\mathrm{b}} \pm 0.03$ \\
Broiler & $20.7^{\mathrm{a}} \pm 1.8$ & $79.3^{\mathrm{b}} \pm 1.7$ & $0.26^{\mathrm{a}} \pm 0.03$ \\
Prob. & $0.05^{-0.05}$ & $0.05^{\circ}$ & 0.05 \\
\hline
\end{tabular}

ab - Means within a column with no common superscript differ significantly.

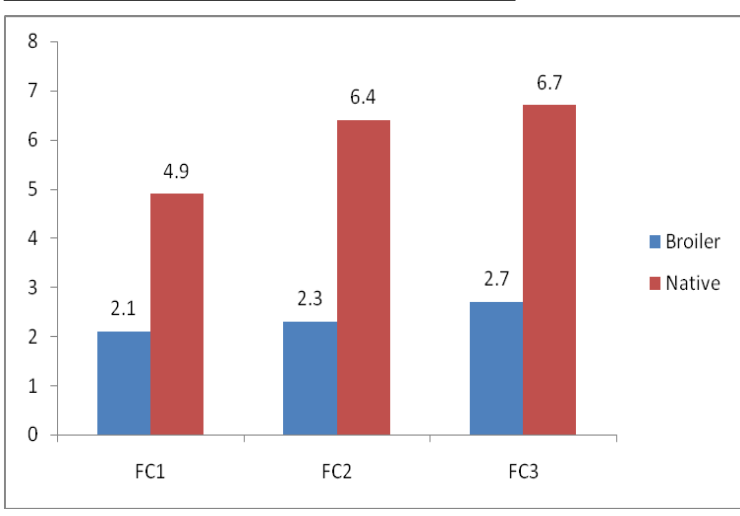

Figure-1. Feed conversion ratio (FC) of broiler and Libyan native chicks during 3- 6 weeks of age

been accompanied by an increase in abdominal fat deposition in broilers [10,11]. In general, local chickens are poor performance in terms of growth rate (hence meat production) and egg production. Most of them are of small adult size and lay small sized eggs when compared to improved commercial broiler or layer birds, respectively [12].

Feed conversion ratios for commercial broiler and Libyan native chicks between three to six weeks of age are shown in Figure-1. The results revealed that the significant deterioration of feed conversion was associated with Libyan native chicks throughout the experimental period comparable with broiler ones. The difference was more pronounced with age progress. As known, both body weight and growth rate are a mirror for feed conversion trait. So that, the deterioration of native chicks body weight was due to the deterioration of feed conversion character. Similarly, the Egyptian native chickens had lower growth rate, poor feed efficiency and lower meat yield [13]. Using the same broiler strain, the feed conversion ratio from 3 to 6 weeks of age was close to the average of feed conversion of the current study (2.5) [14]. Generally, the poultry companies operating in full swing for the development and improvement of

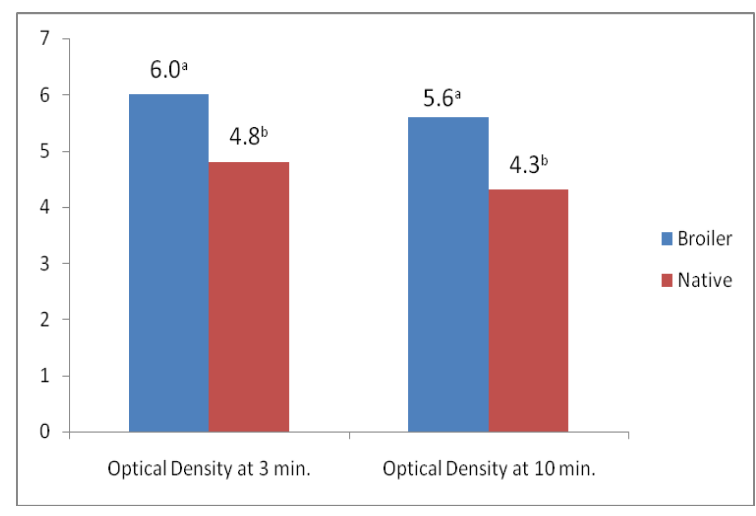

Figure-2. Phagocytic ability of broiler and Libyan native chicks $O D$ increase percentage $=\{(O D$ reading at a considered time - OD reading at zero $\mathrm{min}$ ) / OD reading at zero $\mathrm{min}\} * 100$

broiler strains, especially in economic characteristics such as growth rate, feed conversion ratio and viability.

Regarding phagocytic activity, the defensive functions of phagocytosis come into effect immediately upon the invasion by the foreign materials, whereas the $T$ cells needs time to be stimulated and proliferate before they respond to the invasion [15]. The Phagocytic activity was measured by injection of Indian ink into the birds of the two chicken genetic lines and comparing their ability to clear the injected carbon from blood circulation over a period. An increase in the percentage of optical density (OD) value would be indicative of more carbon present in the sample at the time of quantification, in turn less phagocytosis. Figure-2 showed the effect of genetic group of chicken on phagocytic ability. It could be observed that the Libyan native chicks had significantly lower levels of carbon particles in their blood circulation at 3 and 10 minutes post injection as compared to broiler group. Hence, the phagocytic ability of Libyan native chicks was more efficient compared to the broiler chick ones. The phagocytic activity plays an important role in disease resistance. Birds with higher macrophage phagocytic potential and nitrite production could protect against bacterial, viral, and parasitic infections 
Comparative study on some immunological traits in two different genetic groups of chicken

Table-3. Blood profile of native and broiler chicks

\begin{tabular}{llll}
\hline Trait & Native & Broiler & Prob. \\
\hline PCV , \% & $31.7 \pm 2.0$ & $34.5 \pm 0.77$ & NS \\
WBC, $\times 10^{3}$ & $21.9^{\mathrm{b}} \pm 3.9$ & $26.3^{\mathrm{a}} \pm 1.7$ & 0.001 \\
RBC, $\times 10^{6}$ & $2.6 \pm 0.19$ & $2.7 \pm 0.10$ & $\mathrm{NS}$ \\
$\mathrm{Hb}, \mathrm{g} / \mathrm{dl}$ & $11.1 \pm 0.74$ & $12.3 \pm 0.19$ & $\mathrm{NS}$ \\
$\mathrm{MCV}(\mathrm{fl})$ & $122.1 \pm 1.85$ & $126.4 \pm 1.1$ & $\mathrm{NS}$ \\
$\mathrm{MCH}(\mathrm{pg})$ & $42.7^{\mathrm{b}} \pm 0.63$ & $45.2^{\mathrm{a}} \pm 0.77$ & 0.03 \\
MCHC (\%) & $35.0 \pm 0.29$ & $35.8 \pm 0.49$ & $\mathrm{NS}$ \\
\hline
\end{tabular}

ab - Means within a column with no common superscript differ significantly.

[16]. The phagocytosis might be under the influence of $B$ complex [6]. It is interesting to note that the different genetic origin between broiler and Libyan native chicks may be led to different phagocytic responses. Several researchers have reported that phagocytic activity of chickens is genetically regulated $[6,15,17$, 18,19].

Table-2 shows the effect of genetic group of chicken on heterophils, lymphocytes and $\mathrm{H} / \mathrm{L}$ ratio. It could be seen that the Libyan native chicks had significantly lower heterophils percentage compared to the broiler ones. Opposite trend was noticed for lymphocytes percentage, where, the Libyan native chicks had significantly higher lymphocytes percentage compared to broiler strain. Contrarily, under the Thailand conditions, there was no significant difference between Thai indigenous chicken and broiler chicken in both heterophils and lymphocytes percentages [20]. It is important to note that the heterophils increase and lymphocytes decrease when birds are stressed, so that the ratio between them is an index of response to stressors [21]. There is a genetic component to heterophils and lymphocyte responses to stressors [22] and their ratio has been used as a selection criterion for heat resistance in chickens [23]. Likewise, the different genetic background between the two genetic groups of chicken may be played an important role in the immunocompetence of white blood corpuscles. The genetic variation may exist in the immunocompetence of heterophils [22]. The Libyan native chicks had significantly lower $\mathrm{H} / \mathrm{L}$ ratio compared to the broiler strain. This result indicated that the Libyan chicks were less stressful compared to the others under the current environmental conditions. The $\mathrm{H} / \mathrm{L}$ ratio is a recognized measure of stress in birds $[7,23]$ that has become a valuable tool in stress research, especially when combined the convenience and repeatability of automated blood cell count [24]. Under the Iranian conditions, The H/L ratios of broiler (Ross 308 strain) as a control group were less (0.19) [25] and (0.16) [26] as compared to the estimation of the current study.
This finding also indicate that the genetic background play an important role in the inheritance of $\mathrm{H} / \mathrm{L}$ ratio trait.

Blood profile is very important to evaluate the health status of man and animals. Data presented in Table- 3 revealed that there was no significant difference between the two genetic groups in erythrocytic values (packed cell volume, red blood corpuscles, hemoglobin level, mean value of corpuscular volume and mean value of corpuscular hemoglobin concentration) except the mean value of corpuscular volume. Concerning white blood corpuscles, the broiler chicks had significantly higher WBC count as compared to native chick counterparts. In contrast, the significant difference between Thai indigenous chickens and broilers was observed in hemoglobin and MCHC traits, while the other hematological characters did not statistically differ in two genetic groups of chicken [20].

\section{Conclusion}

It was expected that the broiler chickens were superior in productive traits (body weight and feed conversion ratio) as compared to native chickens. On the other hand, the superiority in immunological abilities such as phagocytic activity and $\mathrm{H} / \mathrm{L}$ ratio (as stress measure) was obtained by Libyan native chickens. This study recommend that it is important to pay more attention on Libyan native chickens and using different crossbreeding and selection methods to produce meat and egg native lines for improving its productive traits besides keeping and benefit its outstanding immunological abilities.

\section{Author's contribution}

Author read and approved the final manuscript.

\section{Acknowledgements}

The author wish to express thanks to Dr. Kadry El-Bakry, Faculty of Science, Sebha University for his effort regarding Lab work. I also want to thank Agriculture and Science Colleges teamwork for their 
help on the field trial.

\section{Competing interest}

The author declare that he has no conflict of interest.

\section{References}

1. Horst, P., Mathur, P.K. (1989). Position of local fowl for tropically oriented breeding activities. Genotype $\mathrm{X}$ environment interactions in poultry production, Jouy-en-Josas (France) May, 9- 11, 1989 Ed. INRA, pp. $159-174$.

2. Mahrous, M., Galal, A., Fathi, M.M., Zein El-Dein, A. (2008). Impact of naked neck $(\mathrm{Na})$ and frizzle $(\mathrm{F})$ genes on growth performance and immunocompetence in chickens. International Journal of Poultry Science, 7: 45- 54.

3. Fathi, M.M., Ali, R. A., Qureshi, M. A. (2003). Comparison of immune responses of inducible Nitric Oxide Synthase (iNOS) hyper-and hypo responsive genotypes of chickens. International Journal of Poultry Science, 2: 280-286.

4. Sarker, N., Yamaguchi, S., Nishibori, M., Tsudzuki, M., Yamamoto, Y. (1999). Effect of divergent selection for serum IgM and IgG levels on the change in gene frequency of blood group systems and blood protein loci in chickens. Animal Science Journal, 70:421-428.

5. Wimmers, K., Ponsukili, S., Hardge, T., Valle-Zarate, A., Mathur, P.K., Horst, P. (2000). Genetic distinctness of African, Asian and South American local chickens. Animal Genetic, 31: 159- 165.

6. Cheng, S., Lamont, S.J. (1988). Genetic analysis of immunocompetence measures in a white Leghorn chicken line. Poultry Science, 67: 989-995.

7. Gross, W.B., Siegel, P.B. (1983). Evaluation of the heterophil/lymphocyte ratio as a measure of stress in chickens. Avian Diseases, 27: 972-979.

8. SAS Institute (1998). SAS/STAT User's Guide: Statistics. Ver. 6.0, SAS Institute Inc., Cary, NC, USA.

9. Nassar, F.S., Moghaieb, R.E.A., Abdou, A.M., Stino, F.K.R. (2012). Microsatellite markers associated with body and carcass weights in broiler breeders. African Journal of Biotechnology, 11:3514-3521.

10. Uemoto, Y., Sato, S., Odawara, S., Nokata, H., Oyamada, Y., Taguchi, Y., Yanai, S., Sasaki, O., Takahashi, H., Nirasawa, K., Kobayashi, E. (2009). Genetic mapping of quantitative trait loci affecting growth and carcass traits in F2 intercross chickens. Poultry Science, 88: 477-482.

11. Howie, J.A., Avendano, S., Tolkamp, B.J, Kyriazakis, I. (2011). Genetic parameters of feeding behavior traits and their relationship with live performance traits in modern broiler lines. Poultry Science, 90: 1197-1205.

12. Gondwe TNP (2004). Characterization of local chicken in low input-low output production systems: is there scope for appropriate production and breeding strategies in Malawi? PhD thesis, Georg-
August-Universität Göttingen, Germany.

13. Galal, A., El-Safty, S.A., Ali, U.M. (2007). Incorporating some marker genes in Dandarawi chicken to improve: 1 . Growth performance and carcass characters. Proceedings of $4^{\text {th }}$ World Poultry Conference, Sharm El-Sheikh, Egypt, pp. 59-74.

14. Emadi, M., Kaveh, K., Jahanshiri, F., Hair-Bejo, M., Ideris, A., Alimon, A. (2010). Dietary tryptophan effects on growth performance and blood parameters in broiler chicks. Journal of Animal and Veterinary Advances, 9: 700-704.

15. Lamont, S.J. (1986). Genetic association of reticuloendothelial activity in chickens. Proc. 3rd world Congress on Genet. Applied to Livestock Production. Agricultural Communications, University of Nebraska, Lincoln, NB. Vol. XI: 643-647.

16. Qureshi, M.A., Yu, M., Saif, Y.M. (2000). A novel "small round virus" inducing poult enteritis and mortality syndrome and associated immune alterations. Avian Disease, 44: 275-283.

17. Qureshi, M.A., Taylor Jr. R.L. (1993). Analysis of macrophage function in Rous sarcoma-induced tumor regressor and progressor 6.B congenic chickens. Veterinary, Immunology and Immunopathology. 37: 285-294.

18. El-Safty, S.A., Fathi, M.M., Galal, A., Al-Rishan, S.S. (2010). The impact of genetic differences on growth performance and immunocompetence of broiler chicken strains under hot ambient temperatures. Journal of Sebha University (Pure and Applied Sc.), Libya, 9: 5- 24.

19. El Syaid, A.G., Kamel, I., Mahrous, M.Y. (2011). Productive performance and immunocompetence parameters of naked neck and normally feathered chicken genotypes got from different maternal lines. Egyptian Poultry Science, 31: 379- 392.

20. Orawan, C., Aengwanich, W. (2007). Blood cell characteristics, hematological values and average daily gained weight of Thai indigenous, Thai indigenous crossbred and broiler chickens. Pakistan Journal of Biological Sciences, 10: 302- 309.

21. Siegel, P.B. (1995). All roads lead through animal genetics. pp. 135-140 in: Proceeding offarm Jay Lush to genomics: Visions for animal and genetics. Iowa State University. Ames. JA.

22. Gross, W.B., Siegel, P.B. (1985) Selective breeding of chickens for corticosterone response to social stress. Poultry Science, 64: 2230- 2233.

23. Al-Murrani, W.K., Kassab, A., Al-Sam, H.Z., AlAThari, A.M. (1997). Heterophil/Lymphocyte ratio as a selection criterion for heat resistance in domestic fowls. British Poultry Science, 38: 159-163.

24. Post, J., Rebel, J.M.J., Ter Huurne, A.A.H.M. (2003). Automated blood cell count in broiler. Poultry Science, 82: 591-595.

25. Somaieh, N., Nobakht, A., Safamehr, A.R. (2011). The effects of different levels of nettle urtica dioical. (urticaceae) medicinal plant in starter and grower 
feeds on performance, carcass traits, blood biochemical and immunity parameters of broilers.

Iranian Journal of Applied Animal Science, 1: 177- 181.

26. Nobakht, A., Nobakht, M., Safamehr, A.R.

(2012). The effect of different levels of savory medicinal plant (Satureja hortensis L.) on growth performance, carcass traits, immune cells and blood biochemical parameters of broilers. African Journal of A gricultural Research, 7: 1456-1461. 